\title{
Mudanças Pedagógicas no Ensino de Semiologia para Discentes de Medicina
}

\author{
Sandra Maria Barroso Werneck Vilagra \\ Universidade Severino Sombra, Centro de Ciências da Saúde, \\ Curso de Medicina. Mestranda do Mestrado Profissional em Ensino \\ em Ciências da Saúde e do Meio Ambiente - Centro Universitário \\ de Volta Redonda (UNIFOA) \\ sm.vilagra@uol.com.br
}

Maria de Fátima Alves de Oliveira

Doutorado em Ensino de Biociências e Saúde pelo Instituto Oswaldo Cruz. Mestrado em Educação pela Universidade do Estado do Rio de Janeiro, UERJ. Professora do Mestrado Profissional em Ensino em Ciências da Saúde e do Meio Ambiente. Centro Universitário de Volta Redonda (UNIFOA) /Fundação Oswaldo Cruz. bio_alves@yahoo.com

Resumo: As Diretrizes Curriculares Nacionais apontam para a necessidade de melhorias no contexto das praticas que envolvem o processo de ensino, dessa forma o ensino da semiologia médica precisa também se adequar as novas tendências para o atual contexto de ensino aprendizagem. O presente estudo delineia como objeto as mudanças pedagógicas no ensino de semiologia, traz como objetivo identificar novas estratégias de ensino e novos cenários de pratica medica. Trata-se de um estudo observacional descritivo cujo cenário foi o Curso de Medicina da Universidade Severino Sombra e os sujeitos envolvidos foram 65 alunos que cursavam o quarto periodo do curso e que tinham participado do Programa de Aproximação a Prática Médica desde o primeiro período do curso. A coleta de dados se deu por questionário estruturado e os resultados apontaram para a necessidade de continuidade nas mudanças ocorridas o que reforçam as recomendações das Diretrizes Curriculares Nacionais do Curso de Graduação de Medicina, bem como vem corroborando com as melhorias no contexto das praticas pedagógicas e êxito na disciplina de semiologia medica.

Palavras-chave: Ensino médico. Cenários de prática. Mudanças pedagógicas.

\section{Pedagogical Changes in Teaching Semiology to Students of Medicine}

\begin{abstract}
The National curriculum guidelines point to the need for improvements in the context of practices involving the teaching process, thus the teaching of medical semiology must also fit the new trends to the current context of learning. The present study delineates how pedagogical changes object in the teaching of
\end{abstract}


semiology, brings aims to identify new teaching strategies and new scenarios of practicing doctors. It is a descriptive observational study whose scenario was the course of Medicine of the University Severino Sombra and subject involved were 65 students that attending the fourth period of the course and who had participated in the Program approach to medical practice since the first period of the course. Data collection took place by structured questionnaire and the results pointed to the need for continuity in changes which reinforce the recommendations of the National curriculum guidelines for Undergraduate Course of medicine, as well as corroborating comes with improvements in the context of pedagogical practices and success in the discipline of medical semiology.

Keywords: Medical teaching. Practical scenarios. Pedagogical changes.

\section{Introdução}

No início do século XX, o ensino no curso de medicina passou por uma acentuada mudança que repercutiu em todo o sistema educativo, baseado no relatório do educador americano Abraham Flexner em 1910.

Após completar cem anos, o relatório continua a gerar debates e polêmicas. Indubitavelmente, a figura e os aportes de Abraham Flexner são, até hoje, foco de debates apaixonados entre defensores e detratores de suas propostas - uns aclamam seu criador como o grande reformista e transformador da educação médica em todos os tempos, e outros o consideram o principal responsável pela consolidação de um modelo de formação de médicos que nunca conseguiu atender às necessidades de saúde das sociedades onde foi implantado, isto é, em praticamente todo o mundo (Cutolo, 2001).

O adjetivo "flexneriano" é aplicado, geralmente com caráter pejorativo, aos currículos que apresentam uma divisão clara entre um período ou ciclo inicial de disciplinas básicas, seguido de outro dedicado aos estudos clínicos. Esta foi a sua proposta que se tornou mais conhecida, embora não a única. De fato, seu modelo de educação médica resistiu quase cem anos e ainda se encontra em vigência na maior parte das escolas médicas do mundo (Tomey, 2002).

As críticas recorrentes ao setor da saúde, que aconteceram com maior intensidade e freqüência a partir da década de 1960 em todo o mundo, pelo que se denominou a "crise da medicina", evidenciaram a falta de compromisso com a realidade e as necessidades da população (Nunes, 1983).

A Associação Brasileira de Educação Médica (Abem), fundada em 1962, desde o início questiona e propõe modificações no complexo formador de médicos. Mais recentemente, a Comissão Interinstitucional Nacional de Avaliação do Ensino Médico (CINAEM) avaliou as escolas médicas, formulando diagnósticos sombrios e extremamente preocupantes. Reflexões sobre a educação médica acumularam argumentos necessários e favoráveis à necessidade de mudanças na educação médica no Brasil.

A partir de 2001, quando foram instituída as Diretrizes Curriculares Nacionais (DCN) 
dos Cursos de Graduação de Medicina pelo Ministério da Educação, o ensino médico começou a sofrer mudanças para contemplar o novo perfil de formandos; um ensino envolvido com habilidades e competências orientadas pela atual política educacional e com processo pedagógico centrado no aluno.

Segundo as Diretrizes Curriculares Nacionais do Curso de Graduação em Medicina (DCN) - Resolução CNE/CES No. 04, de 07 de novembro de 2001, Art. $3^{\circ}$ : O curso de Graduação de Medicina tem como perfil do formando egresso/profissional o médico, com formação generalista, humanista, critica e reflexiva, capacitado a atuar, pautado em princípios éticos, no processo de saúde-doença em seus diferentes níveis de atenção, com ações de promoção, prevenção, recuperação e reabilitação à saúde, na perspectiva da integralidade da assistência, com senso de responsabilidade social e compromisso com a cidadania, como promotor da saúde integral do ser humano.

O artigo $4^{\circ}$ das DCN diz que a formação do médico tem por objetivo preparar o profissional para o exercício das seguintes competências e habilidades: atenção à saúde, tomada de decisões, comunicação, liderança, administração e gerenciamento e educação permanente. Para o desenvolvimento dessas competências a estrutura do curso de Medicina deve utilizar metodologias que privilegiem a participação ativa do aluno na construção do conhecimento e a integração entre os conteúdos.

As abordagens pedagógicas progressivas de ensino aprendizagem vem sendo construídas e implicam formar profissionais como sujeitos sociais com competências éticas, políticas e técnicas e dotados de conhecimento, raciocínio critico, responsabilidade e sensibilidade para as questões da vida e da sociedade, capacitando-os para intervirem em contextos de incertezas e complexidades (Mitre et al., 2008).

Segundo Mitre e colaboradores (2008) as metodologias ativas utilizam a problematização como estratégia de ensino-aprendizagem, com o objetivo de alcançar e motivar o discente, pois diante do problema, ele se detém, examina, reflete, relaciona a sua história e passa a dar novo significado as suas descobertas.

Em decorrência desse processo, fez-se necessário que as Faculdades de Medicina reformulassem sua matriz curricular para que o aluno desde o primeiro período inicie sua inserção na prática médica. A estrutura curricular implantada almeja capacitar o aluno a visualizar o paciente como um todo, apto a compreender os múltiplos fatores que alteram o equilíbrio indivíduo - ambiente e a entender a saúde no seu sentido mais amplo (DCN, 2001).

Com essa visão foi implantada em 2008 no Curso de Medicina da Universidade Severino Sombra na cidade de Vassouras - RJ, a nova matriz curricular na qual, o ensino de Semiologia Médica, foi integrado ao Programa de Aproximação a Pratica Médica (PAPM) que possui um eixo horizontal no currículo fazendo parte da Unidade de Ensino de Temas Integralizadores de Propedêutica e Terapêutica, integrando o ensino da Semiologia Médica do primeiro ao quinto período. Seguindo dessa maneira a orientação das Diretrizes Curriculares, pois faz a inserção do aluno na prática médica desde o primeiro período.

Os conteúdos essenciais para o Curso de Graduação em Medicina devem estar relacionados com todo o processo saúde-doença do cidadão, 
da família e da comunidade, integrado à realidade epidemiológica e profissional, proporcionando a integralidade das ações do cuidar em medicina. Devem contemplar: compreensão e domínio da propedêutica médica - capacidade de realizar história clínica, exame físico, conhecimento fisiopatológico dos sinais e sintomas; capacidade reflexiva e compreensão ética, psicológica e humanística da relação médico-paciente; (DCN Art. $6^{\circ}$. Paragafro IV)

O PAPM tem como objetivo proporcionar ao aluno o contato com o paciente, realizando a grande arte da medicina que é a Historia Clínica e o exame físico, possibilitando o desenvolvimento do seu raciocínio clínico para o diagnóstico do paciente. O ensino da Semiologia Médica visa obter as informações da anamnese dos pacientes do modo mais completo e fidedigno possível, além de reunir os achados do exame físico, realizado de maneira judiciosa e ordenado, como princípio essencial ao raciocínio clínico que irá conduzir ao diagnóstico. Isto constitui a base da Medicina, sem a qual não se podem formar médicos (Santos, 1999).

O ensino de Semiologia Médica precisa adequar às novas metodologias, mas não pode perder a grande importância, que é o ensino a beira do leito. O estudo junto ao paciente é uma atividade com potencial educativo, que continua merecendo incentivo nas escolas médicas. Desta maneira, o paciente à beira do leito torna-se uma fonte inesgotável de ensinamentos e aprendizados, exercitando habilidades fundamentais da Medicina, como o desenvolvimento do raciocínio clínico, a prática da abordagem ao paciente no leito, bem como a destreza de ver, ouvir e sentir um paciente (Ribeiro \& Amaral, 2008).

O início da prática médica nos currículos tradicionais correspondia ao início da fase clínica do curso que ocorria no quarto período, nesse modelo o aluno começava o contato com o paciente tardiamente, até então o seu contato prévio era somente com cadáveres e animais de laboratório. No modelo atual de ensino o contato com o paciente ocorre desde o primeiro período despertando desde o inicio a relação médico paciente. Com base nessas considerações, o objetivo principal deste estudo foi realizar uma investigação a respeito de novas estratégias de ensino e de novos cenários de práticas no Programa de Aproximação a Prática Médica (PAPM) do Curso de Medicina da Universidade Severino Sombra (USS).

\section{Metodologia}

Trata-se de uma pesquisa observacional descritivo de natureza qualitativa, cujos sujeitos envolvidos foram discentes que cursavam o quarto período do Curso de Medicina. O cenário de estudo foi a USS Vassouras/Rio de Janeiro. O critério de escolha dos discentes se deu por estarem inseridos na nova matriz curricular desde o primeiro período e por ser o local de trabalho da autora. Os alunos assinaram o termo de consentimento livre esclarecido para participar da pesquisa. Para avaliarmos os resultados deste novo modelo entre os alunos, utilizamos o questionário com questões objetivas e subjetivas sobre as novas metodologias desenvolvidas no curso. Esse questionário foi aplicado aos alunos na sala de aula no final do semestre. Os alunos responderam ao questionário individualmente, sem discussão entre eles e entregaram ao professor após o término. O questionário 
apresentado consistia em questões sobre avaliação da utilização das oficinas de práticas e do uso do laboratório de habilidades.

As oficinas de práticas segundo Pimenta \& Anastasiou, 2002, se caracterizam como uma estratégia do fazer pedagógico onde o espaço de construção e reconstrução do conhecimento são as principais ênfases. É lugar de pensar, descobrir, reinventar, criar e recriar, favorecido pela forma horizontal na qual a relação humana se dá. No final das atividades os estudantes materializam suas produções. No PAPM as oficinas funcionam com grupo de 10 alunos orientados por um professor - tutor que expõe os objetivos da oficina que constam de revisões de aulas praticas a beira do leito, nesse momento o aluno junto com o seu grupo realiza com os seus conhecimentos prévios a arte e técnica da história clínica e do exame físico do paciente e no final da oficina descreve esses dados que vão compor um estudo de caso para discussão.

O Laboratório de Habilidades ( $\mathrm{LH})$ representa uma alternativa de apoio pedagógico, atuando como uma atividade antecipatória das práticas de treinamento de habilidades com o paciente, preparando o estudante para o exercício técnico e intelectual de sua futura profissão, pautado nos preceitos da bioética. Segundo Pezzi e Pessanha Neto, 2008, para aprender a clinicar efetivamente, os estudantes de Medicina e médicos devem ter acesso a essa importante ferramenta de ensino- aprendizagem que, inevitavelmente, fará parte do arsenal didático obrigatório de todas as escolas médicas e hospitais do Brasil. Utilizamos o LH com pré-requisito para as aulas práticas de semiologia a beira do leito, essa utilização é feito com manequins simuladores, incluindo também manequins simuladores de ausculta cardíaca e respiratória.

\section{Resultados e Discussão}

Foram analisados 65 questionários, nos quais foram avaliadas a oficina de prática e o uso do laboratório de habilidades utilizadas no Programa desde o primeiro período. Em relação à oficina de prática foram questionados se necessitaram rever o conteúdo estudado para participar da atividade $84,61 \%$ disseram que sim. Na pergunta seguinte foi avaliado se o novo método acrescentou algum aprendizado no conteúdo anteriormente aprendido 96,92\% dos docentes disseram que sim, conforme observado no Gráfico 01.

Gráfico 1- (A) A maioria necessita rever o conteúdo para participar da oficina. (B) A maioria informa que algum conteúdo foi acrescentado ao aprendizado após oficina.

A

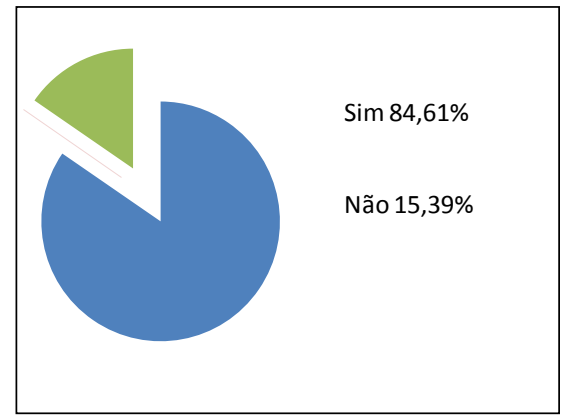

B

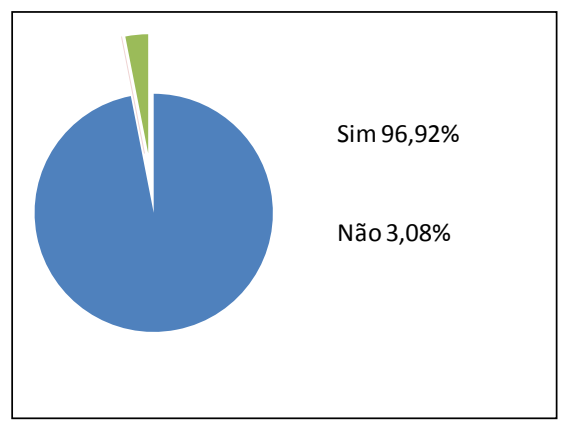


As oficinas de praticas, ou como o equivalente "workshop", isto é lugar de trabalho indica a natureza eminentemente pratica ou aplicada dessa técnica, com objetivos específicos que se definem em termos de que os estudantes aprenderão a fazer melhor o que já sabiam (Bordenave \& Pereira, 1991).

Questionados sobre a necessidade de orientação de um professor para atingir os objetivos que foram propostos na oficina $64,61 \%$ dos discentes disseram não necessitar de um professor, conforme retrata a Gráfico 2.

\section{Gráfico 2 - Necessidade de um professor para orientar nos objetivos propostos.}

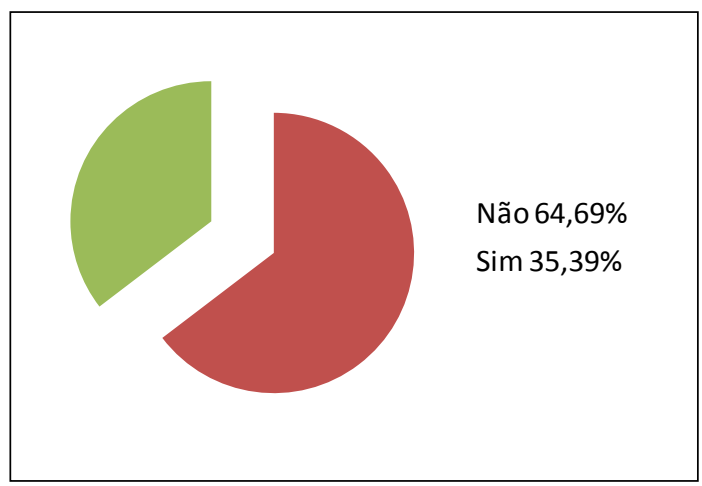

Podemos observar que com a utilização das oficinas o estudante passa a assumir um papel cada vez mais ativo, deixando de ser mero receptor de conteúdos, buscando efetivamente conhecimentos relevantes aos problemas e aos objetivos da aprendizagem. Segundo Komatizu, Zanolli \& Lima, 1998, novos objetivos educacionais devem ser transformados, entre eles o de "ensinar - aprender com observação passiva dos estudantes, para o aprender a aprender, com a participação ativa dos aprendizes, ou seja, do centrado no professor para o centrado no estudante".

A segunda parte do questionário referia-se a avaliação do novo cenário de ensino, o laboratório de habilidades. Foram questionados se acharam válida a utilização do laboratório de habilidades como pré-requisito para as aulas práticas a beira do leito de Semiologia Cardiovascular e Respiratória, a maioria dos discentes disseram que sim, como retrata o Gráfico 3.

\section{Gráfico 3 - Validade do uso do laboratório de habilidades antes das aulas práticas a beira do leito}

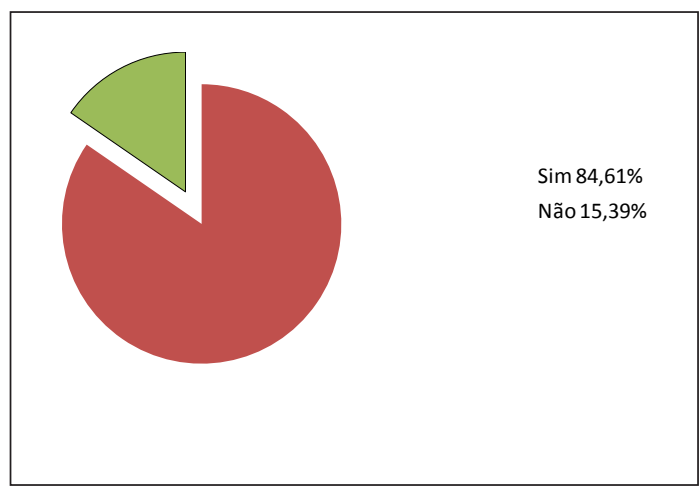


Um dos argumentos utilizados para justificar essa resposta foi que realizando a técnica primeiro no manequim e depois no paciente, eles se sentiam mais seguros. Por outro lado os que não aprovaram a utilização do laboratório de habilidades disseram que os motivos são que os manequins não são como os pacientes, pois a relação não fica pessoal e por isso preferem as aulas diretamente a beira do leito com o paciente.

Conforme Ribeiro \& Amaral, 2008, o ensino à beira do leito torna-se uma fonte inesgotável de ensinamentos e aprendizados, exercitando habilidades fundamentais da Medicina, portanto nosso programa não tem o intuito de deixar de praticar as aulas a beira do leito, o laboratório de habilidades é apenas um novo cenário de ensino no qual o aluno desenvolverá a habilidade do exame físico para posteriormente praticar no paciente, sem, contudo deixar de exercer a grande arte da medicina que é o ouvir e sentir um paciente desenvolvendo a cada dia a relação médico paciente.

\section{Conclusões}

Com base nas mudanças que vem ocorrendo no ensino médico podemos observar que a inserção das oficinas de práticas passam a ser mais uma estratégia que podemos utilizar no nosso cotidiano uma vez que foi bem aceita pelos alunos.

Consideramos também que o uso do laboratório de habilidades com simuladores passam a fazer parte do ensino médico, pois contribuem com a melhora do ensino facilitando a aprendizagem e passando a ser utilizada como mais um cenário para as atividades de práticas médicas.

Portanto, as mudanças no ensino médico, a partir dos objetivos propostos pelas DCN do Curso de Graduação de Medicina, propõem nova construção didática pedagógica. Nesse sentido foi oportuno avaliarmos essas mudanças instituídas em nosso programa de ensino da Semiologia Médica, onde podemos observar que houve uma boa aceitação por parte dos discentes nas novas praticas de ensino e que eles estão receptivos as mudanças na construção do seu conhecimento. 


\section{Referências}

Bordenave JD \& Pereira AM. (1991) A estratégia de ensino aprendizagem. $26^{\mathrm{a}}$ ed. Petrópolis: Vozes; 2005.

Cutolo LR. (2001). Estilo de pensamento em educação médica: um estudo do currículo do curso de graduação em medicina da UFSC. Florianópolis; Mestrado [Dissertação] - Universidade Federal de Santa Catarina

Diretrizes Curriculares Nacionais do Curso de Graduação de Medicina - CONSELHO NACIONAL DE EDUCAÇÃO. (2001). Câmara de Educação superior. Resolução CNE/CES 4/2001. Diário Oficial da União. Brasília, 09 de novembro de 2001. Seção 1, p. 38.

Komatzu RS, Zanolli M, Lima VV. (1998). Aprendizagem baseada em problemas. In: Marcondes E, Gonçalves E, organizadores. Educação médica. São Paulo: Sarvier; 223-37.

Mitre SM et al. (2008). Metodologias ativas de ensino-aprendizagem na formação profissional em saúde: debates atuais. Ciênc. saúde coletiva [online]. 13 (2), 21332144.

Nunes ED (org.). (1983). Medicina Social: aspectos históricos e teóricos. São Paulo: Global Editora.

Pezzi L \& Pessanha Neto S. (2008). O laboratório de habilidades na formação médica, Cadernos ABEM - 4, 16-22.

Pimenta SG \& Anastasiou LGC. (2002). Docência no ensino superior. 2. ed. São Paulo: Cortez.

Ribeiro MMF \& Amaral CFS. (2008). Medicina centrada no paciente e ensino médico: a importância do cuidado com a pessoa e o poder médico. Rev. Bras. Educ. Med. [online]. 32(1), 90-97.

Santos JB. (1999). Ouvir o paciente - A anamnese no diagnóstico clínico. Brasília Med. $36(3 / 4), 90-95$.

Santos JB, Pires LL, Silva AE \& Castro NC. (2003). Reflexões sobre o ensino de semiologia médica. Revista Brasileira de Educação Médica. 27(2): 147-152.

Tomey AV. (2002). Abraham Flexner, pionero de la educación médica. Rev Cubana Educ Méd Super. 16(2): 156-63. 